Revue d'histoire de l'Amérique française

REVUE D'HISTOIRE DE L'AMÉRIQUE FRANÇAISE

\title{
LAPOINTE, Richard et Lucille TESSIER, Histoire des \\ Franco-Canadiens de la Saskatchewan. Société historique de la Saskatchewan, 1986.
}

\section{Jacqueline Blay}

Volume 41, numéro 1, été 1987

URI : https://id.erudit.org/iderudit/304531ar

DOI : https://doi.org/10.7202/304531ar

Aller au sommaire du numéro

Éditeur(s)

Institut d'histoire de l'Amérique française

ISSN

0035-2357 (imprimé)

1492-1383 (numérique)

Découvrir la revue

Citer ce compte rendu

Blay, J. (1987). Compte rendu de [LAPOINTE, Richard et Lucille TESSIER, Histoire des Franco-Canadiens de la Saskatchewan. Société historique de la Saskatchewan, 1986.] Revue d'histoire de l'Amérique française, 41(1), 89-91. https://doi.org/10.7202/304531ar d'utilisation que vous pouvez consulter en ligne.

https://apropos.erudit.org/fr/usagers/politique-dutilisation/ 
LAPOINTE, Richard et Lucille TESSIER, Histoire des Franco-Canadiens de la Saskatchewan. Société historique de la Saskatchewan, 1986.

L'histoire des francophones hors Québec est une histoire qui a été négligée par la force des choses, dans l'Ouest surtout. Occupés par les luttes qui devaient assurer leur survivance sur le plan législatif, scolaire, culturel tout autant qu'économique, les francophones hors Québec ont souvent remis à plus tard ou à d'autres le soin de raconter leur mémoire collective. Il y a donc peu d'ouvrages qui se sont penchés sur leurs luttes, leurs succès, mais le plus souvent leurs déboires. L'Histoire des Franco-Canadiens de la Saskatchewan de Richard Lapointe et Lucille Tessier vient combler un vide, et il faut saluer l'initiative de la Société historique de la Saskatchewan qui a permis à ce projet de voir le jour de façon aussi complète. Les fonds d'archives étaient pauvres et il a fallu que les auteurs se transforment en chercheurs et en interviewers pour mettre sur pied un ouvrage qui est «un témoignage à la mémoire des ancêtres venus du Québec, de la France, de la Belgique et des États-Unis».

Le livre est divisé en quatre grands chapitres qui vont de 1885 à aujourd'hui. Mil huit cent quatre-vingt-cinq est une période charnière dans l'Ouest, à cause de la pendaison de Louis Riel. Il était approprié que les auteurs ne s'attardent pas uniquement au chef métis. Les Indiens et les Métis, dépassés par la nouvelle civilisation qui avançait dans l'Ouest, se virent relégués au ban de l'histoire, car le gouvernement canadien n'a pas su les intégrer au Canada moderne. Petit à petit, les Blancs prennent possession des terres et changent le mode de vie mais aussi la société de ce qui est, administrativement parlant, les Territoires du Nord-Ouest. 
Le rôle de l'Église catholique a été des plus importants dans la colonisation française de l'Ouest, et c'est pourquoi Richard Lapointe et Lucille Tessier lui consacrent tout le deuxième chapitre. Car les vues d'Ottawa et celles de l'Église ne concordent pas: Ottawa veut peupler l'Ouest le plus rapidement possible avec des immigrants capables de faire fructifier la terre. Il n'y a pas de considérations linguistiques qui entrent en jeu dans les plans fédéraux, ce qui ne sied pas vraiment à l'Église qui estime que les Canadiens français ont un droit d'aînesse sur ces territoires. Les craintes du clergé ne seront pas apaisées et tous les efforts pour recruter des Franco-catholiques au Québec ou aux États-Unis ne seront pas aussi fructueux que l'Église catholique l'espérait.

Le troisième chapitre est consacré aux premières années de cette nouvelle province baptisée Saskatchewan. Les efforts de recrutement faits au Québec et ailleurs ainsi que les conditions de vie: nouveau type d'agriculture, logement, alimentation, transports, vie sociale et amusements, y sont détaillés. Quiconque n'a pas eu l'occasion de visiter l'Ouest et d'y constater la mentalité très particulière qui a pris souche aux cours de ces années trouvera bien des enseignements en lisant ce chapitre. Dur à la tâche, le Franco-Canadien de la Saskatchewan sait s'adapter aux conditions plus que rudes dans certains cas. Les francophones s'entendent bien avec leurs voisins des autres ethnies et, tout en évoluant dans un milieu majoritairement anglophone, ils sont unis par des liens communs, la langue et la religion.

Il arrivera un moment, cependant, où la bonne volonté, le courage, l'endurance et le travail ne sont pas suffisants pour lutter contre les assauts législatifs destinés à réduire les droits de la minorité francophone. Car, si l'avenir pouvait paraître assuré sur le plan financier, il n'en restait pas moins que l'avenir de la langue n'était pas assuré du tout. Les francophones avaient déjà eu l'expérience, en Ontario comme au Manitoba, du problème posé par la transmission de l'héritage culturel et linguistique dans le cadre d'institutions gérées par une majorité différente sur le plan culturel et linguistique. A la merci de fonctionnaires ou d'hommes politiques qui, dans certains cas, se conduisirent en fanatiques, les francophones se sont regroupés en associations dites nationales. Ces dernières furent dotées de mandats bien spécifiques, et quelquefois agirent comme un ministère parallèle de l'éducation. Tel fut le cas de l'Association catholique franco-canadienne qui dut attendre les années soixante pour relâcher sa vigilance face aux gouvernements provinciaux et pour voir le gouvernement fédéral prêter attention à ces francophones hors Québec qui ont survécu tant bien que mal. La survivance a demandé des outils bien précis et bien concrets et l'hebdomadaire Le patriote de l'Ouest, longtemps jumelé à La liberté du Manitoba pour ensuite devenir l'Eau vive, en fut un. Lorsque les progrès technologiques menacèrent leur survivance culturelle, les Franco-Saskatchewanais durent lutter pied à pied pour obtenir leurs postes de radio et leurs postes de télévision. L'attente fut longue et le chemin semé d'embûches politiques. Le quatrième chapitre raconte ces luttes politico-culturelles et, du même coup, fait ressortir le travail immense accompli par le clergé et par les laïcs qui estimaient plus important que tout de maintenir l'héritage culturel.

L'Histoire des Franco-Canadiens de la Saskatchewan donne plus cependant qu'un tableau d'histoire de l' «autre peuple fondateur». En effet, l'ouvrage est bourré de photos, extraits de lettres, copies de premières pages des quotidiens anglophones ou d'hebdomadaires francophones, reproductions de docu- 
ments originaux, statistiques, tout ce qui peut aider à découvrir un passé qui a encore tant de pertinence à l'heure actuelle. L'histoire des Franco-Canadiens de la Saskatchewan, ou des Fransaskois comme ils sont connus depuis les années soixante-dix, rejoint celle des Franco-Manitobains ou des Franco-Ontariens: c'est une histoire tissée de revendications, de déboires, d'échecs mais aussi de survivance en dépit de tout. L'hostilité politique de la majorité a toujours été un problème auquel les minorités hors Québec ont été confrontées certes, mais l'indifférence des groupes ou des provinces, qui pouvaient aider à cette survivance, a été le facteur qui a le plus handicapé leur croissance.

Il est temps que l'histoire de ces minorités soit connue en dehors des provinces où elles essaient de survivre, et où l'obtention de droits naturels, comme un procès en français, est considérée comme une exception à la règle.

L'ouvrage de Richard Lapointe et de Lucille Tessier ne parle pas des présentes revendications politiques des Fransaskois et c'est, à mon avis, une lacune en ce sens que nous avons l'impression que les luttes sont terminées et que les gouvernements provinciaux prêtent une oreille complaisante aux demandes des francophones. Or ce n'est pas le cas. Les pérégrinations du Père Mercure ne sont pas notées, non plus, et c'est dommage car elles sont instructives à plus d'un titre pour quiconque ne connaît pas l'histoire de la Saskatchewan. Mais les auteurs ont probablement estimé qu'il valait mieux ne pas placer le livre dans un contexte très actuel mais inachevé. C'est un choix qui doit être respecté.

Il est également important que cette histoire des francophones de la Saskatchewan soit traitée par des francophones. Trop souvent ce point de vue francophone a été ignoré par les historiens canadiens, qu'ils soient anglophones ou du Québec. S'il n'a pas été ignoré il a été mal compris, mal perçu ou mal transmis. De plus, lorsque les francophones hors Québec revendiquent des droits qu'ils estiment naturels, en associations provinciales ou en associations nationales, leur cri paraît strident dans le concert national. Or, si les Canadiens en général, et les francophones en particulier, connaissaient l'histoire des descendants de ceux qui ont peuplé tout un pays avant même les vagues d'immigrations gouvernementale, le cri de la revendication paraîtrait pertinent et justifié. Car trop souvent les francophones de l'Ouest ont été oubliés et ceux-ci, faute de moyens et de nombres, n'ont pas réussi à demeurer à l'avant-garde des relations politiques.

L'ouvrage de Richard Lapointe et de Lucille Tessier ne se hasarde pas non plus à envisager l'avenir des Fransaskois, peut-être parce que l'assimilation est une menace plus présente que jamais, peut-être aussi parce que les temps difficiles ne sont pas quelque chose de nouveau pour eux.

Quoiqu'il en soit, l'Histoire des Franco-Canadiens de la Saskatchewan est un ouvrage de base qui peut à juste titre employer à quelques reprises un ton très partisan et exhiber une certaine fierté des pionniers et de leur héritage. Il faut espérer que d'autres historiens seront inspirés par cet ouvrage pour fouiller un peu plus ce récent passé, que ceux qui ne connaissaient pas les détails se renseignent au plus vite, et que ceux qui, concernés par cette histoire, se sentent fiers de leur héritage. 